\title{
Prevalence and risk factors for stroke in a population of Southern Brazil
}

\author{
Prevalência e fatores de risco para AVC numa população do sul do Brasil \\ Leslie Copstein', Jefferson Gomes Fernandes², Gisele Alsina Nader Bastos ${ }^{3}$
}

\begin{abstract}
Stroke is the leading cause of death in many countries of Latin America. Population studies are necessary in this region. Objectives:To evaluate the prevalence of stroke and its risk factors in a population of vulnerable communities of southern Brazil. Methods: Population-based crosssectional study with systematic sampling. Individuals aged 20 and over were included $(n=3,391)$. Individuals with previous diagnosis of stroke or identified by a validate stroke questionnaire were compared with those without stroke in many variables. Results: 285 individuals $(8.4 \%)$ had previous stroke. The group without stroke showed greater average of years of study than the group with stroke $(p<0.001)$. Multivariable analysis identified as risk factors for stroke ( $p<0.05$ ): age from 40 to 59, age from 60 to 79, widowhood, present smoking, previous smoking, hypertension and ischemic heart disease. Conclusion: The findings in this population indicate the need of preventive cost-effective public health policies in Brazil.
\end{abstract}

Key words: stroke, cross-sectional studies, socioeconomic factors, prevalence, Latin America.

\section{RESUMO}

O acidente vascular cerebral (AVC) é a principal causa de morte em muitos países da América Latina. Objetivos: Avaliar prevalência e fatores de risco para AVC em população de comunidades vulneráveis no sul do Brasil. Métodos: Estudo transversal de base populacional com amostragem sistemática. Foram incluídos os indivíduos a partir de 20 anos de idade $(n=3.391)$. Indivíduos com prévio diagnóstico de AVC ou identificados por questionário validado para AVC foram comparados àqueles sem AVC em diversas variáveis. Resultados: 285 indivíduos $(8,4 \%)$ referiram AVC prévio. 0 grupo sem AVC teve maior média de anos de estudo que o grupo com AVC ( $p<0,001)$. Foram identificados como fatores de risco para AVC ( $p<0,05)$ : idade de 40 a 59 anos, idade de 60 a 79 anos, viuvez, tabagismo no presente, tabagismo no passado, hipertensão arterial sistêmica e doença isquêmica do coração. Conclusão: São necessárias no Brasil políticas de saúde pública preventivas e custo-efetivas.

Palavras-Chave: acidente vascular cerebral, estudos transversais, fatores socioeconômicos, prevalência, América Latina.

Stroke is a pathological entity with high prevalence and severe impact in affected individuals, both in developed countries and those in developing. However, two-thirds of deaths caused by stroke occur in low and middle-income countries ${ }^{1}$.

Currently, stroke can be considered the greatest public health problem in Brazil and in many countries of Latin America $^{1,2}$. Although scarce, Brazilian epidemiological studies show elevated mortality ${ }^{3-5}$ and high prevalence of sequels in survivors, such as physical disability, post-stroke depression and dementia ${ }^{6,7}$. Brazilian data are not known, but in United States, in 2008, the cost of care with disability caused by stroke was estimated in 18.8 billion dollars, while productivity loss and premature deaths had cost of 15.5 billion dollars ${ }^{8}$.

In addition, in the last 20 years, many studies have reported decreasing incidence of stroke in developed countries ${ }^{9}$. The reasons for this trend are not totally known, but it can be attributed to better knowledge and management of risk factors. Even in middle and low-income countries there have been reports of cases of stroke reduction during this period, although less pronounced as compared to developed countries ${ }^{1,10}$. It is possible that, in Latin America, the reduction is related to better control of risk factors, but also to technological advances and improvement in the quality of health services ${ }^{1,5}$.

\footnotetext{
Study carried out at Institute of Education and Research, Moinhos de Vento Hospital, Porto Alegre RS, Brazil.

${ }^{1}$ Graduate Program in Family and Community Medicine, School of Health Management, Moinhos de Vento Hospital, Porto Alegre RS, Brazil;

${ }^{2}$ Institute of Education and Research, Moinhos de Vento Hospital, Porto Alegre RS, Brazil;

${ }^{3}$ School of Health Management, Moinhos de Vento Hospital, Porto Alegre RS, Brazil.

Correspondence: Leslie Copstein; Rua Reis Louzada 189 / apto. 802; 90630-130 Porto Alegre RS - Brasil; E-mail: Icopstein@gmail.com

Support: The research was conducted in the framework of the philanthropic project "Development of techniques of operation and management of health services in a intramunicipal region of Porto Alegre - Restinga and Extremo-Sul districts", in accordance with the program of support for the institutional development of the Sistema Único de Saúde (PROADI-SUS), signed between the Brazilian Ministry of Health and the Hospital Association Moinhos de Vento. Conflict of interest: There is no conflict of interest to declare.

Received 24 August 2012; Received in final form 28 October 2012; Accepted 05 November 2012.
} 
Several factors are now well established as risk for stroke. For ischemic stroke, they have been identified as risk factors: age, hypertension (HTN), dyslipidemia, diabetes mellitus, smoking, asymptomatic carotid stenosis and non-valvular atrial fibrillation ${ }^{11}$. HTN and oral anticoagulation therapy are the factors most frequently associated to intracerebral hemorrhage $^{12}$, while HTN, smoking and alcohol consumption have been reported as risk factors to subarachnoid hemorrhage ${ }^{13}$.

Nevertheless, the heterogeneity of the pathology and peculiarities of different countries and populations may evidence new risks for stroke, modifiable or not. Socioeconomic variables ${ }^{14}$, ethnic factors, dietary habits and even endemic diseases, like Chagas disease in Brazil ${ }^{15}$, can pose risks for different subtypes of stroke. Thus, steady and standardized surveillance, performed in different regions, will provide information to enable collective health strategies for prevention and management of risk factors.

All the former elements considered, the present study aimed to assess the prevalence of stroke survivors, their sociodemographic profile and the occurrence of risk factors in the population of a vulnerable community in Southern Brazil, a middleincome country with a highly racially mixed population.

\section{METHODS}

From July through December 2009, an epidemiological survey was performed in a capital city in Southern Brazil, with the purpose of planning a net of health services to be offered to this community, in which approximately 100,000 people live in a vulnerable situation. Part of the data collected was analyzed to produce this cross-sectional study, which included all individuals aged 20 or over.

Porto Alegre City has 1,409,939 inhabitants ${ }^{16}$ and 110 districts. The survey was carried out in 5 districts, whose assemblage has 121 census tracts, of which 117 are household sectors and were included in the sample. In them, 32,067 homes were identified and 29,929 were inhabited houses. For the population-based survey, 1,750 households were selected. The quotient set the value of the systematic jump, equal to 17 . The sample size was calculated in 440 individuals, with $95 \%$ level of confidence.

The survey was disclosed to the population through letter of presentation, posters and local radio stations and newspapers.

Refusals were considered when the selected subject denied answering the questions at least three times and losses when the selected subject was not found by the same number of times. For quality control, new interviews were carried out by phone on $10 \%$ of the total sample, with a simplified questionnaire.

The variables analyzed in this study are from the following questions: (a) Have you ever had stroke, thrombosis or cerebral ischemia? (b) Have you ever had paralysis on one side of your body that lasted longer than a day? (c) Have you ever had paralysis on one side of your face that lasted longer than a day? (d) Have you ever had difficulty speaking which lasted longer than a day?

Therefore, two groups were considered: individuals who reported symptoms or clinical diagnosis compatible with any kind of stroke and those who did not have such symptoms. The two groups were then compared with regard to risk factors for stroke.

To obtain the results, the following independent variables were analyzed:

- Sociodemographic data - age (in years), gender, skin color (as observed by the interviewer), current marital status, degree of literacy, years of study and family income.

- Current height and weight (self-reported, respectively in centimeters and kilograms) and body mass index (BMI, calculated in $\mathrm{kg} / \mathrm{m}^{2}$ ).

- Prior or current smoking/smoking time (months or years)/number of cigarettes per day.

- Have had medical diagnosis of hypertension/hypertensive parents history.

- Have had medical diagnosis of diabetes mellitus and/or high cholesterol.

- Evaluation of physical activity as the International Physical Activity Questionnaire (IPAQ) (short version).

- Having been informed by a physician to have angina, infarction or heart attack, for individuals aged 40 and over.

- Evaluation of chest pain or discomfort as the Rose angina questionnaire (short version), for individuals aged 40 and over.

- Evaluation of peripheral occlusive arterial disease as the Rose questionnaire on intermittent claudication, for individuals aged 40 and over.

- Evaluation of alcoholic beverages consumption as the Alcohol Use Disorders Identification Test (AUDIT).

\section{Statistical analysis}

Quantitative variables were presented as absolute data and percentages. Categorical variables were analyzed by Chisquare test. Multivariable analysis was done by Poisson regression with robust error variance.

The significance level used was $\mathrm{p}<0.05$ and all the analyses were performed in SPSS version 15.0.

This study was approved by the Ethics Committee of Moinhos de Vento Hospital under Protocol 2009/28, and all individuals who had accepted to take part of the survey signed an informed consent.

\section{RESULTS}

\section{Data from studied population}

From 3,699 individuals who were eligible to participate in the study, 3,391 (91.7\%) agreed to answer the questionnaire. 
The majority were women (55.9\%), Caucasian (77.7\%), literate $(91.9 \%)$ and were married or had a common-law marriage $(62.2 \%)$.

Age ranged from 20 to 96 years [mean 44.13, median 43, standard deviation (SD) 16.024, quartile first (Q1) 30, quartile third (Q3) 56]. Family income ranged from zero to 40,000 reais/month (mean 2.045.88, median 1.550, SD 2.132.84, Q1 950, Q3 2.480) and years of study ranged from zero to 22 (mean 8.04, median 8, SD 3.518, Q1 5, Q3 11).

Of the individuals, $29.8 \%$ reported to be hypertensive, $28.4 \%$ reported having hypertensive father and $45.6 \%$ reported they had hypertensive mother.

The percentage of the ones who reported to be diabetic was $9.1 \%$, and $18.9 \%$ reported present hypercholesterolemia.

Among the individuals aged 40 and over, 10.8\% reported previous diagnosis of infarction, angina or symptoms of angina consistent with the Rose questionnaire for chest pain. Only $2 \%$ reported symptoms consistent with peripheral occlusive arterial disease, as the Rose questionnaire for intermittent claudication.

As to the level of physical activity, $55.6 \%$ of the respondents informed being inactive or insufficiently active. Of the individuals, $5.2 \%$ had the BMI above normal.

Of the individuals, $55.7 \%$ stated never having smoked and 98.3\% informed do not consume alcoholic beverages or have low consumption risk.

\section{Data relating to stroke}

The individuals who reported diagnosis or symptoms consistent with prior stroke was 285 ( $8.4 \%$ of the sample) (Tables 1 and 2).

There was no statistically significant difference between the groups with and without stroke with respect to gender, ethnicity, family income, level of literacy, family history of hypertension, diabetes mellitus, hypercholesterolemia, BMI, physical activity level, peripheral occlusive arterial disease or alcohol consumption.

The group without stroke had the average years of study (8.12, SD 3.45) significantly greater than the group with stroke (7.09, SD 4.05) $(\mathrm{p}<0.001)$. For the multivariable analysis, we decided to categorize this variable into five groups (Table 3). The group with 9 to 11 years of study was statistically significant as a protective factor against stroke [prevalence ratio $(P R)=0.625$, confidence interval 95\%CI 0.418-0.935] $(p<0.05)$.

In multivariable analysis, were statistically significant risk factors for stroke $(\mathrm{p}<0.05)$ : age 40 to 59 years $(\mathrm{PR}=1.580$, 95\%CI 1.106-2.256), age 60 to 79 years ( $\mathrm{PR}=1.940$, 95\%CI $1.271-$ 2.962), marital status widower ( $\mathrm{PR}=1.369,95 \% \mathrm{CI} 1.004-1.866)$, smoking at the present ( $\mathrm{PR}=1.351,95 \% \mathrm{CI} 1.040-1.755)$, smoking in the past $(\mathrm{PR}=1.398,95 \% \mathrm{CI} 1.077-1.814)$, hypertension $(\mathrm{PR}=2.443$, 95\%CI $1.861-3.208)$ and coronary artery disease ( $\mathrm{PR}=1.843$, 95\%CI 1.425-2.384). This last variable included all the individuals aged 40 and over that reported diagnosis of angina, infarction or heart attack or symptoms of angina as the Rose questionnaire.

Among individuals with marital status widower, there was no statistically significant difference between genders.

Among the smoker respondents, there was no significant difference between the groups with and without stroke on the number of cigarettes smoked per day. The time of smoking in years was divided into categories; the $\chi^{2}$ test of independence showed statistical significance for the time of smoking equal or greater than 40 years as risk for stroke (PR=1.135, 95\%CI $1.060-1.215)(\mathrm{p}<0.001)$.

\section{DISCUSSION}

Although some stroke prevalence studies have already been carried out in Brazil ${ }^{17-19}$, the data is still insufficient to provide a broad overview of the problem and the burden it represents.

Table 1. Demographical and socioeconomic data about adult population in vulnerable community. Porto Alegre, Rio Grande do Sul, 2009

\begin{tabular}{|c|c|c|}
\hline Variable & $\mathrm{n}$ & $\%$ \\
\hline \multicolumn{3}{|l|}{ Gender } \\
\hline Male & 1,496 & 44.1 \\
\hline Female & 1,895 & 55.9 \\
\hline \multicolumn{3}{|l|}{ Skin color (observed) } \\
\hline Caucasian & 2,636 & 77.7 \\
\hline Non-caucasian & 750 & 23.3 \\
\hline \multicolumn{3}{|l|}{ Age (complete years) } \\
\hline $20-39$ & 1,399 & 42.7 \\
\hline $40-59$ & 1,278 & 39.0 \\
\hline $60-79$ & 551 & 16.8 \\
\hline$\geq 80$ & 51 & 1.6 \\
\hline \multicolumn{3}{|l|}{ Marital status } \\
\hline Married or in common-law marriage & 2,108 & 62.2 \\
\hline Single & 744 & 21.9 \\
\hline Divorced or separated & 280 & 8.3 \\
\hline Widowed & 259 & 7.6 \\
\hline \multicolumn{3}{|l|}{ Literacy } \\
\hline Literate & 1,729 & 91.9 \\
\hline Just sign & 59 & 3.1 \\
\hline Illiterate & 93 & 4.9 \\
\hline \multicolumn{3}{|l|}{ Complete years of study } \\
\hline $0-4$ & 570 & 17.9 \\
\hline $5-8$ & 1,274 & 40.0 \\
\hline $9-12$ & 1,095 & 34.4 \\
\hline$\geq 12$ & 245 & 7.7 \\
\hline \multicolumn{3}{|l|}{ Family income (reais/month) } \\
\hline Until 1,019 & 999 & 29.5 \\
\hline $1,020-3,060$ & 1,850 & 54.5 \\
\hline $3,061-7,650$ & 489 & 14.4 \\
\hline $7,651-15,300$ & 38 & 1.1 \\
\hline$\geq 15,300$ & 15 & 0.5 \\
\hline
\end{tabular}


Table 2. Descriptive analysis of health variables in adult population of vulnerable community. Porto Alegre, Rio Grande do Sul, 2009

\begin{tabular}{|c|c|c|}
\hline Variable & $\mathrm{n}$ & $\%$ \\
\hline \multicolumn{3}{|l|}{ Stroke (previous diagnosis or symptoms) } \\
\hline Yes & 285 & 8.4 \\
\hline No & 3,106 & 91.6 \\
\hline \multicolumn{3}{|l|}{ Hypertension } \\
\hline Yes & 1,012 & 29.9 \\
\hline No & 2,378 & 70.1 \\
\hline \multicolumn{3}{|l|}{ Hypertensive father } \\
\hline Yes & 964 & 28.4 \\
\hline No & 2,426 & 71.6 \\
\hline \multicolumn{3}{|l|}{ Hypertensive mother } \\
\hline Yes & 1,545 & 45.6 \\
\hline No & 1,846 & 54.4 \\
\hline \multicolumn{3}{|l|}{ Diabetes mellitus } \\
\hline Yes & 310 & 9.1 \\
\hline No & 3,081 & 90.9 \\
\hline \multicolumn{3}{|l|}{ Hypercholesterolemia } \\
\hline Yes & 642 & 18.9 \\
\hline No & 2,749 & 81.1 \\
\hline \multicolumn{3}{|l|}{$\begin{array}{l}\text { Myocardial infarction (previous diagnosis, } \\
\text { individuals over } 40 \text { years-old) }\end{array}$} \\
\hline Yes & 74 & 2.2 \\
\hline No & 1,877 & 55.4 \\
\hline \multicolumn{3}{|l|}{$\begin{array}{l}\text { Angina (previous diagnosis, individuals } \\
\text { over } 40 \text { years-old) }\end{array}$} \\
\hline Yes & 171 & 5.0 \\
\hline No & 1,780 & 52.5 \\
\hline \multicolumn{3}{|l|}{$\begin{array}{l}\text { Angina (Rose questionnaire for chest pain, } \\
\text { individuals over } 40 \text { years-old) }\end{array}$} \\
\hline Yes & 121 & 3.6 \\
\hline No & 1,829 & 53.9 \\
\hline \multicolumn{3}{|l|}{$\begin{array}{l}\text { Peripheral vascular disease (Rose } \\
\text { questionnaire for intermittent } \\
\text { claudication, individuals over } 40 \text { years-old) }\end{array}$} \\
\hline Yes & 69 & 2.0 \\
\hline No & 3,322 & 98.0 \\
\hline \multicolumn{3}{|l|}{ Physical activity (IPAQ criteria) } \\
\hline Inactive or insufficiently active & 1,884 & 55.6 \\
\hline Active or very active & 1,507 & 44.4 \\
\hline \multicolumn{3}{|l|}{ Body mass index } \\
\hline Low & 55 & 1.6 \\
\hline Normal & 1,356 & 40.0 \\
\hline Overweight & 1,189 & 35.1 \\
\hline Obesity & 682 & 20.1 \\
\hline \multicolumn{3}{|l|}{ Cigarette smoking } \\
\hline Yes (present) & 929 & 27.4 \\
\hline Yes (past) & 574 & 16.9 \\
\hline No & 1,888 & 55.7 \\
\hline \multicolumn{3}{|l|}{$\begin{array}{l}\text { Alcohol beverages consumption (AUDIT } \\
\text { questionnaire) }\end{array}$} \\
\hline No consumption or low risk consumption & 3334 & 98.3 \\
\hline $\begin{array}{l}\text { Harmful or hazardous drinking, } \\
\text { or probable alcohol dependence }\end{array}$ & 57 & 1.7 \\
\hline
\end{tabular}

IPAQ: International Physical Activity Questionnaire; AUDIT: Alcohol Use Disorders Identification Test.
Because of systematic sampling, probability proportional to the census tract and low percentages of losses and refusals, this study has good inference power, so that the results can be generalized to similar communities.

However, being a cross-sectional study, it is vulnerable to the phenomenon of reverse causality, in which it is not possible to determine what happened first: exposure to risk factor or disease. Being also a population-based study, it is subject to ecological bias, once is not feasible to establish whether the individuals exposed are the same who have the disease. In addition, the level of exposure found will represent an average and not individual values, but the results obtained here can later lead to more detailed analytical studies.

In addition to the analysis of risk factors, this study aimed to estimate the prevalence of non-fatal cases in the community, in accordance to the international strategy of the World Health Organization (WHO) surveillance on stroke ${ }^{20}$. Modified from the Neurological Screening Questionnaire for Cerebrovascular Disease (NSQ-CVD $)^{17}$, the data collection instrument consists of a question about previous diagnosis of stroke and three more questions about symptoms related to stroke, of easy recognition by the general population. The cases were considered positive when any of the questions had affirmative answer.

The NSQ-CVD questionnaire validation study was conducted in an elderly population (from 80 years) in the municipality of Veranópolis, Brazil, in 1996 ${ }^{17}$. The NSQ-CVD resembles almost in its entirety to the questionnaire used in this study, having only one more question: presence of numbness on one side of the body or face, lasting more than a day. In the validation study, this question had the lowest sensitivity (20\%). The cases were also considered positive if there was affirmative answer to any of the questions. The application of the full questionnaire reached $100 \%$ sensitivity, specificity of $50.9 \%$, positive predictive value of $28 \%$ and negative predictive value of $100 \%$.

More recently, Abe et al. ${ }^{21}$ conducted the study called EMMA (Portuguese acronym for Mortality and Morbidity of Cerebrovascular Accident Study), to validate a questionnaire for stroke screening in a vulnerable community of São Paulo city, Brazil. The EMMA questionnaire ${ }^{21}$ consisted of six questions, one about previous diagnosis of stroke confirmed by a physician and five about symptoms (including visual deficit). Individuals from 35 years were included; the cases were considered positive when there were affirmative answer to two or more questions, if the previous diagnosis of stroke was included or to three of any questions, with confirmation by physician or not. The sensitivity found was $72.7 \%$, specificity of $94.4 \%$, positive predictive value of $92.9 \%$ and negative predictive value was $77.3 \%$.

The symptoms questionnaires for stroke are therefore already validated instruments for screening non-fatal cases in epidemiological studies, cost-effective and suitable to primary 
Table 3. Stroke prevalence, crude analysis and adjusted analysis of risk factors according to independent variables of the study in adults of a vulnerable community. Porto Alegre RS, 2009.

\begin{tabular}{|c|c|c|c|c|c|}
\hline \multirow{2}{*}{ Variable } & \multirow{2}{*}{ Stroke (\%) } & \multicolumn{2}{|c|}{ Crude analysis } & \multicolumn{2}{|c|}{ Adjusted analysis } \\
\hline & & PR $(95 \% \mathrm{Cl})$ & $\mathrm{p}$-value & PR $(95 \% \mathrm{Cl})$ & $\mathrm{p}$-value \\
\hline Age (years) & & & $<0.001$ & & $<0.05$ \\
\hline $20-39$ & 3.4 & 1.00 & & 1.00 & \\
\hline $40-59$ & 9.2 & 2.708 (1.960-3.742) & & $1.580(1.106-2.256)$ & \\
\hline $60-79$ & 18.4 & $5.394(3.901-7.458)$ & & 1.940 (1.271-2.962) & \\
\hline$\geq 80$ & 14.5 & $4.275(2.129-8.584)$ & & $1.439(0.689-3.006)$ & \\
\hline Marital status & & & $<0.001$ & & $<0.05$ \\
\hline Married/Common-Law & & & & & \\
\hline Marriage & 7.5 & 1.00 & & 1.00 & \\
\hline Single & 5.4 & $0.717(0.512-1.004)$ & & $1.045(0.751-1.464)$ & \\
\hline Divorced/Separated & 11.8 & $1.572(1.104-2.240)$ & & $1.141(0.799-1.627)$ & \\
\hline Widower & 20.8 & $2.782(2.101-3.683)$ & & 1.369 (1.004-1.866) & \\
\hline Years of study & & & $<0.001$ & & $<0.05$ \\
\hline $0-1$ & 18.8 & 1.00 & & 1.00 & \\
\hline $2-5$ & 11.1 & $0.591(0.432-0.809)$ & & $0.770(0.560-1.059)$ & \\
\hline $6-8$ & 6.9 & $0.366(0.257-0.521)$ & & $0.712(0.487-1.043)$ & \\
\hline $9-11$ & 5.1 & $0.274(0.190-0.394)$ & & $0.625(0.418-0.935)$ & \\
\hline$\geq 12$ & 7.3 & $0.389(0.240-0.631)$ & & $0.856(0.520-1.407)$ & \\
\hline Hypertension & & & $<0.001$ & & $<0.001$ \\
\hline No & 4.3 & 1.00 & & 1.00 & \\
\hline Yes & 18.0 & $4.152(3.298-5.227)$ & & $2.443(1.861-3.208)$ & \\
\hline Ischemic heart disease & & & $<0.001$ & & $<0.001$ \\
\hline $\begin{array}{l}\text { No (individuals from } 40 \text { y-o without prior diagnosis of } \\
\text { angina or infarction or symptoms of angina) }\end{array}$ & 6.7 & 1.00 & & 1.00 & \\
\hline $\begin{array}{l}\text { Yes (individuals from } 40 y \text {-o with prior diagnosis of } \\
\text { angina or infarction or symptoms of angina) }\end{array}$ & 27.0 & $4.043(3.210-5.093)$ & & $1.843(1.425-2.384)$ & \\
\hline Cigarette smoking & & & $<0.001$ & & $<0.05$ \\
\hline No & 6.7 & 1.00 & & 1.00 & \\
\hline Current & 9.0 & 1.355 (1.040-1.765) & & $1.351(1.040-1.755)$ & \\
\hline Prior & 13.1 & $1.958(1.494-2.565)$ & & $1.398(1.077-1.814)$ & \\
\hline Time of smoking (years) & & & $<0.001$ & & \\
\hline Up to 4 years & 7.5 & 1.00 & & & \\
\hline $5-19$ & 6.4 & 0.989 (0.943-1.037) & & & \\
\hline $20-39$ & 11.5 & 1.040 (0.989-1.094) & & & \\
\hline$\geq 40$ & 20.2 & 1.135 (1.060-1.215) & & & \\
\hline
\end{tabular}

PR: prevalence ratio; $\mathrm{Cl}$ : confidence interval; $y$-o: years-old.

care environments. The etiology of symptoms, such as hemiplegia or hemiparesis, in adult patients is limited to stroke and head trauma in most communities ${ }^{20}$. The questionnaires possibly underestimate milder cases, but can identify cases with the highest degree of physical disability and require more resources for rehabilitation ${ }^{21}$.

In this study, we observed prevalence of $8.4 \%$ of self-reported stroke. Prevalence of $6.6 \%$ was found in the study conducted by Abe et al. in São Paulo, with similar methodology ${ }^{18}$. The study performed by Friedrichs et al. in Veranópolis city included individuals from 80 years and found prevalence of $4.9 \%{ }^{17}$. Study conducted by Ferri et al. ${ }^{22}$ in urban and rural regions of China, India and Latin America (Cuba, Dominican Republic, Mexico, Peru and Venezuela) assessed individuals from 65 years and found gross prevalence of stroke between 6 and 9\% in urban areas of Latin America. Two other studies in South America showed lower prevalence, but in rural areas: 1.8\% in Bolivia (adults from 35 years) ${ }^{23}$ and $0.8 \%$ in Argentina (adults from 40 years) ${ }^{24}$.

The identification of risk factors for any pathology in a community is an essential point for planning collective health strategies. Many of the risk factors for stroke are well known, but their distribution in each community should be carefully evaluated. In addition, other factors previously unsuspected may be noted.

In this study, multivariable analysis identified age from 40 to 79 years as a risk for stroke. The group from 80 years had no statistically significant risk, but there were a small number of individuals. It is well established that the greater the age, the greater the risk for ischemic stroke ${ }^{10}$. However, in this population, the risk is already evidenced in an early age.

Widowhood had statistically significant association with occurrence of stroke in multivariable analysis. Several 
epidemiological studies mention this association ${ }^{25}$ although the reasons for its occurrence are not yet clear. Some researchers suggest this association is more frequent in males ${ }^{26}$, which was not found in this study.

Individuals with longer school education had observed lower occurrence of stroke, but there was no statistical significance regarding the monthly income. Several studies point to be the occurrence of stroke inversely proportional to socioeconomic factors of a population, such as monthly income and education level ${ }^{27}$. Such factors influence access to health services, lifestyle, understanding of pathologies and adherence to treatments ${ }^{1}$.

Smoking is causative factor of various pathological conditions, such as different types of cancer, chronic respiratory diseases, heart disease and stroke. In 1988, the Framingham study identified smoking as independent risk factor for stroke, proportional to the number of cigarettes smoked per $\mathrm{day}^{28}$. Recent studies have identified smoking as risk factor for atherosclerosis of intracranial vessels, which is frequent cause of stroke ${ }^{29}$. The consumption of cigarettes is still positively associated with subarachnoid hemorrhage as independent risk factor and increasing the risk in the concomitant existence of hypertension ${ }^{12}$. In this study, current and prior smoking were identified in multivariable analysis as risk factors for stroke and also was the time of smoking equal or greater 40 years.

Hypertension also was confirmed as a risk factor for stroke in multivariable analysis. It was considered hypertensive those individuals who had a previous diagnosis of hypertension; the blood pressure was not measured nor it was questioned use of antihypertensive drugs. Thus, it is possible that the number of hypertensive had been underestimated. Hypertension is the risk factor for stroke more often identified in Latin American studies, although there are differences in definitions and methods ${ }^{1}$.

Coronary artery disease (CAD) was searched in individuals from 40 years of age. It was considered as carrier of CAD the individual already informed about the diagnosis of angina, infarction or heart attack or even one that depicts symptoms consistent with angina, according to the short version of Rose questionnaire. In multivariable analysis of this study, $\mathrm{CAD}$ was a factor associated with stroke. Recent studies have suggested that the atherosclerotic process occur simultaneously in carotid, coronary and cerebral arteries ${ }^{30}$, but the present study performs only the screening of symptoms and does not distinguish between the types of stroke.

Diabetes mellitus and hypercholesterolemia are pathologies notoriously established as risk factors for cardiovascular and cerebrovascular disease of ischemic type, but in this study they were not statistically significant. Because they may be asymptomatic conditions, it is possible that many cases of hypercholesterolemia and chronic hyperglycemia are unknown on the part of individuals included in the survey.

In conclusion, this study found high prevalence of stroke survivors in the population of a vulnerable community in Porto Alegre city, Brazil. In this population, were identified as stroke risk factors: age, widowhood, current and prior smoking, hypertension and coronary artery disease. Higher number of years of study has been identified as a protective factor against stroke. It is highlighted the occurrence of modifiable risk factors and hence the need and opportunity for implementation of cost-effective public health policies.

\section{References}

1. Lavados PM, Hennis AJM, Fernandes JG, et al. Stroke epidemiology, prevention, and management strategies at a regional level: Latin America and the Caribbean. Lancet Neurol 2007;6:362-372.

2. World Health Organization. The World Health Report 2002. Reducing risks, promoting healthy life. Geneva: World Health Organization, 2002.

3. De Carvalho JJ, Alves MB, Viana GÁ, et al. Stroke epidemiology, patterns of management, and outcomes in Fortaleza, Brazil: a hospital-based multicenter prospective study. Stroke 2011;42:3341-3346.

4. Goulart AC, Benseñor IM, Fernandes TG, et al. Early and one-year stroke case fatality in São Paulo, Brazil: Applying the World Health Organization's Stroke STEPS. J Stroke Cerebrovasc Dis 2011. Epub ahead the print.

5. Cabral NL, Gonçalves AR, Longo AL, et al. Trends in stroke incidence, mortality and case fatality rates in Joinville, Brazil: 1995-2006. J Neurol Neurosurg Psychiatry 2009;80:749-754.

6. Glacomin KC, Peixoto SV, Uchoa E, Lima-Costa MF. A populationbased study on factors associated with functional disability among older adults in the Great Metropolitan Belo Horizonte, Minas Gerais State, Brazil. Cad Saude Publica 2008;24:1260-1270.

7. Carod-Artal FG, Ferreira Coral L, Trizotto DS, Menezes Moreira C. Poststroke depression: prevalence and determinants in Brazilian stroke patients. Cerebrovasc Dis 2009;28:157-165.
8. Roger VL, Go AS, Lloyd-Jones DM, et al. Heart diseases and stroke statistics - 2012 update: a report from the American Heart Association. Circulation 2012;125:188-197.

9. Mirzaei M, Truswell AS, Arnett K, Page A, Taylor R, Leeder SR. Cerebrovascular disease in 48 countries: secular trends in mortality 1950-2005. J Neurol Neurosurg Psychiatry 2012;83:138-145.

10. Rodríguez T, Malvezzi M, Chatenoud L, et al. Trends in mortality from coronary and cerebrovascular diseases in the Americas: 1970-2000. Heart 2006;92:453-460.

11. Pinto A, Tuttolomondo A, Di Raimondo D, Fernandez P, Licata G. Cerebrovascular risk factors and clinical classification of stroke. Semin Vasc Med 2004;4:287-303.

12. Elliott J, Smith M. The acute management of intracerebral hemorrhage: a clinical review. Anesth Analg 2010;110:1419-1427.

13. Linderkleiv H, Sandvei MS, Romundstad PR, et al. Joint effect on modifiable risk factors on the risk of aneurysmal subarachnoid hemorrhage: a cohort study. Stroke 2012;43:1885-1889.

14. Furukawa TS, Mathias TA, Marcon SS. Stroke mortality by residence and place of death: Paraná State, Brazil, 2007. Cad Saude Publica 2011;27:327-334.

15. Lima-Costa MF, Matos DL, Ribeiro AL. Chagas Disease predicts 10-year stroke mortality in community-dwelling elderly: the Bambui cohort study of aging. Stroke 2010;41:2477-2482. 
16. Instituto Brasileiro de Geografia e Estatística. Dados do Censo 2010 publicado no Diário Oficial da União do dia 04/11/2010. Brasilia, 2010. [cited 2012 Apr 29]. Available at http://www.ibge.gov.br/home/ estatistica/populacao/censo2010/tabelas_pdf/total_populacao_ rio_grande_do_sul.pdf

17. Friedrichs, Maurício André Gheller. Epidemiologia das doenças cerebrovasculares em uma população de idosos da cidade de Veranópolis, RS [tese] [cited 2012 Apr 04]. Available at http:// capesdw.capes.gov.br/capesdw/resumo.html?idtese $=200277420$ $05019014 \mathrm{P5}$

18. Abe IM, Lotufo PA, Goulart AC, Benseñor IM. Stroke prevalence in a poor neighbourhood of são paulo, brazil: applying a stroke symptom questionnaire. Int J Stroke 2011;6:33-39.

19. Pereira AB, Alvarenga H, Pereira RS Jr, Barbosa MT. Stroke prevalence among the elderly in Vassouras, Rio de Janeiro State, according to data from the Family Health Program. Cad Saude Publica 2009;25:1929-1936.

20. World Health Organization. The WHO stepwise approach to stroke surveillance. Overview and Manual (V. 2.0). Noncommunicable Diseases and Mental Health [cited 2012 Mar 05]. Available at www.who.int/entity/ncd_surveillance/steps/en

21. Abe IM, Goulart AC, Santos Júnior WR, Lotufo PA, Benseñor IM. Validation of a stroke symptom questionnaire for epidemiological surveys. São Paulo Med J 2010;128:225-231.
22. Ferri CP, Schoenborn C, Kalra L, Acosta D, et al. Prevalence of stroke and related burden among older people living in Latin America, India and China.J Neurol Neurosurg Psychiatry 2011;82:1074-1082.

23. Nicoletti A, Sofia V, Giuffrida S, et al. Prevalence of stroke: a door-to-door survey in rural Bolivia. Stroke 2000;31:882-885.

24. Melcon $\mathrm{CM}$, Melcon CO. Prevalence of stroke in an Argentine community. Neuroepidemiology 2006;27:81-88.

25. Moon JR, Kondo N, Glymour MM, Subramanian V. Widowhood and mortality: a meta-analysis. PLoS One 2011;6:e23456.

26. Va P, Yang WS, Nechuta S, et al. Marital status and mortality among middle age and elderly men and women in urban Shangai. PLoS One 2011;6:e26600.

27. Cabral NL, Longo A, Moro C, et al. Education level explains differences in stroke incidence among city districts in Joinville, Brazil: a threeyear population-based study. Neuroepidemiology 2011;36:258-264.

28. Wolf PA, D’Agostino RB, Kannel WB, Bonita R, Belanger AJ. Cigarette smoking as a risk factor for stroke. The Framingham Study. JAMA 1988;259:1025-1029.

29. Kim DE, Lee KB, Jang IM, et al. Associations of cigarette smoking with intracranial atherosclerosis in the patients with acute ischemic stroke. Clin Neurol Neurosurg 2012;144:1243-1247.

30. Shetty S, George P, Venkatesha BM, Alva J. A study to correlate carotid intima thickness by B-mode ultrasonography in patients documented with coronary artery disease. Heart Views 2011;12:157-160. 